\title{
Cost based risk analysis to identify inspection and restoration intervals of hidden failures subject to aging
}

\author{
Alireza Ahmadi and Uday Kumar
}

\begin{abstract}
This paper aims to develop a cost rate function (CRF) to identify the optimum interval and frequency of inspection and restoration of aircraft's repairable components which are undergoing aging and whose failures are hidden, i.e. are detectable by inspection or upon demand.

The paper considers two prevalent strategies, namely Failure Finding Inspection (FFI) and a combination of FFI with restoration actions (FFI+Res), for both the "non-safety effect" and the "safety effect" categories of hidden failures. Asbad-as-old (ABAO) inspection effectiveness and as-good-asnew (AGAN) restoration effectiveness are considered. In case of repair due to findings by inspection, as-bad-as-old repair effectiveness is considered.

The proposed method considers inspection and repair times, and takes into account the costs associated with inspection, repair and restoration, and the potential losses due to the inability to use the aircraft (maintenance downtime). It also considers the cost associated with accidents caused by the occurrence of multiple failure. The approach used in this study for risk constraint optimization is based on the mean fraction of time during which the unit is not functioning within inspection intervals (MFDT) and the average interval unavailability behaviour within the restoration period.

In the case of an operational limit, when it is not possible to remove the unit for restoration, or one needs to use the unit longer than the expected operating time, the paper introduces an approach to analyzing the possibility of and conditions for providing an extension to the restoration interval that satisfies the risk constraints and the business requirements at the same time.
\end{abstract}

Index Terms - Cost rate function, Combination of maintenance strategy, Failure Finding Inspection, Hidden failures, Inspection interval, Mean Fractional Dead Time, Multiple failure, MSG-3, Restoration task, Risk constraint optimization, Interval extension.

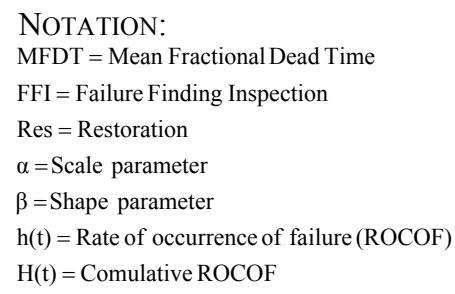

Manuscript received September 07, 2009. The Authors are with the Division of Operation and Maintenance Engineering Luleå University of Technology, Luleå, Sweden. (e-mail: alireza.ahmadi@Itu.se ; uday.kumar@ltu.se).

Digital Object Identifier TR2009-231.

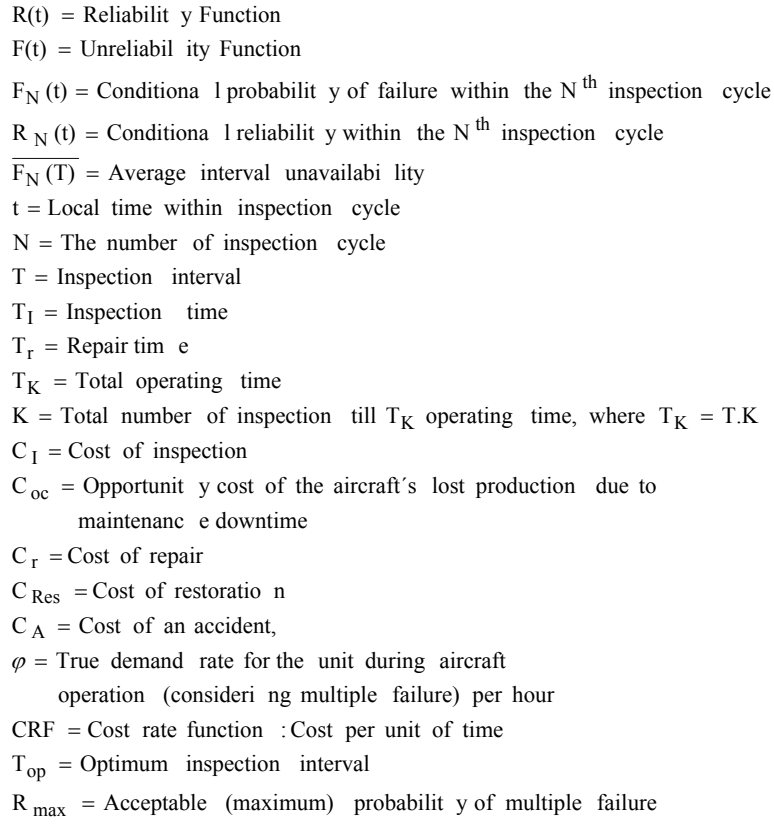

\section{INTRODUCTION}

$\mathrm{O}$ $\mathrm{NE}$ aspect of maintenance programme analysis is to develop tasks to preserve and assure the availability of hidden functions (or off-line functions). These types of functions are used intermittently or so infrequently, which their failure will not be evident to the operating crew during the performance of normal duties [1]. Examples are the failure of a pressure relief valve, ram air turbine, fire detector, fire extinguisher or standby radio. Termination of the ability to perform a hidden function is called hidden failure.

Hidden failures are not known unless a demand is made on the hidden function (as a result of an additional failure or second failure, i.e. a trigger event), or until a specific operational check, test or inspection is performed. Hidden failures are divided up into the "safety effect" and the "nonsafety effect" categories. The failure of a hidden function in the "safety effect" category involves the possible loss of the equipment and/or its occupants, i.e. a possible accident. The failure of a hidden function in the "non-safety effect" category may entail possible economic consequences due to the undesired events caused by a multiple failure (e.g. operational interruption or delays, a higher maintenance cost, and secondary damage to the equipment). As a common practice in aviation maintenance, hidden failures 
are analyzed as part of a multiple failure and are considered as failures that do not have any undesirable consequence when they occur on their own. A multiple failure is defined as "a combination of a hidden failure and a second failure or a demand that makes the hidden failure evident"[1].

Since the arrival of a demand occurs at random, it is essential that the item should be operative, i.e. available, upon demand. Hence, depending on the criticality and consequences of multiple failures and the demand rate, a specific level of availability of the hidden function is needed. When the item is in a non-operational state when required to function, then it is termed unavailable [2]. Obviously, the probability of a multiple failure can be reduced by reducing the unavailability of the hidden function. For highly reliable systems it is often more appropriate to focus on unavailability rather than on availability [3]. If a hidden failure (undetected failure) occurs while the system is in a non-operating state, the system's availability can be influenced by the frequency at which the system is inspected. If inspection finds the system inoperable, a maintenance action is required to repair it [4].

A common practice in aircraft maintenance programme development, ATA MSG-3 [5] is used to develop scheduled aircraft maintenance requirements. According to MSG-3, it is required to define a scheduled "failure finding inspection (FFI)" to detect the functional failure that has already occurred, but was not evident to the operating crew. FFI aims to assure the availability of a hidden function and to eliminate or reduce the probability of occurrence of multiple failures [5]. In some instances it may not be possible to find a single FFI task which on its own is effective in reducing the risk of failure to a tolerable level. In these cases it may be necessary to employ a combination of tasks such as FFI and scheduled restoration. Each of these tasks must be applicable in its own right and in combination they must be effective. In practice, a combination of tasks is rarely used, and is considered for failures with safety consequences, as a stopgap pending redesign [1]. However, as the present study shows, depending on the characteristics of the failure, the mode of maintenance execution and the cost parameter, selecting a combination of tasks may result in a more effective strategy even for the "non-safety effect" failure category. This may be due to the complexity of decision making and task interval development.

Hence, all the available maintenance opportunities should be analyzed and the ultimate decision should be based on cost-benefit analyses made to select the most cost-effective strategy among applicable options. These challenges can be addressed more accurately by quantitative models. Some studies relevant to the optimization of Failure Finding Inspection can be found through literatures. Some of the relevant literatures are presented in the following paragraphs.

Jardine [6] proposed a model considering AGAN inspection and repair effectiveness, and the known and constant inspection time $\left(\mathrm{T}_{\mathrm{i}}\right)$ and repair time $\left(\mathrm{T}_{\mathrm{r}}\right)$. The AGAN assumption for inspection and repair is reasonable when there is no trend in the data [7, 8]. In this case the average unavailability of the unit is the same in subsequent intervals.
Vaurio [9], [10] studied the time-dependent unavailability of standby units under ageing in a nuclear power plant, considering different inspection and repair effectiveness. A general formalism has been developed for selecting the economically optimal test and maintenance intervals, with and without risk constraints. Furthermore, Vaurio [11] extended his previous studies and developed unavailability and cost models for normal operating units subject to hidden failure and periodically inspected and maintained, considering "like-old" tests and "like-new" repairs.

A common practice in aviation maintenance is to ground the aircraft, i.e. stop the flight operation, to perform maintenance. Grounding the aircraft also entails costs for the airline, and hence one needs to consider inspection and repair times and include their effect in the optimization model.

Rausand and Vatn [12] discussed the consequences of choosing a Weibull life distribution instead of an exponential distribution when calculating the unavailability of hidden functions for a surface-controlled subsurface safety valve in an offshore oil and gas production well. They used the Mean Fractional Dead Time (MFDT) concept to estimate the unavailability of hidden function within inspection intervals. They proposed age-based replacement policies to balance the risk and operational cost on the basis of calculations using a Weibull distribution in which attention was paid to the integration between the proposed replacement policies and the work entailed by the replacement policies. They considered the component to be as-good-as-new after replacement and disregarded test and replacement time. Inflation and other financial effects were regarded as negligible.

Barroeta and Modarres [13] studied the optimal inspection policy for periodically tested repairable components undergoing an aging process, in combination with an overhaul after a certain number of inspections using a so-called cost rate function. They considered the condition of the components to be as-bad-as-old after inspection/testing and repair and as-good-as-new after an overhaul, i.e. after a renewal process. They assume that the test and repair time may increase after every test cycle, and that the associated cost of overhaul and the possible loss due to the unavailability of the component (the cost of an accident) are constant. Inflation and other financial effects are negligible. However, risk limits were not considered.

More recently, Lienhardt et al. [14] also studied the problem of selecting a suitable failure finding maintenance strategy for a repairable aircraft system that is subject to hidden failures that do not have any operational consequences, i.e. do not interrupt aircraft operation when they occur, such as the failure of warning devices. They developed an optimization model based on the Markov model, considering the maintenance cost rate as an objective function and using the risk of corrective maintenance as the constraint function. They applied their model for a constant failure rate, i.e. exponential distribution of failure, or a random type of failure.

Since, in practice, performing all the individual maintenance tasks at their own optimal intervals is not practical, the method presented in this paper aims to provide an optimization-based decision support, to enhance the 
capability of taking correct and effective decisions for maintenance interval assignment, in accordance with the predefined intervals in a form of check package e.g. the $A_{1}$, $\mathrm{A}_{2}, \mathrm{~B}, \mathrm{C}$, or D check packages, a common terminology used in aviation industry.

The method presented in this paper is based on the cost rate function (CRF) and identifies the optimum interval and frequency of inspection and restoration that minimize the cost per aircraft flight hour. It considers two prevalent strategies, namely Failure Finding Inspection (FFI) and a combination of FFI with restoration actions (FFI+Res), for both the "non-safety effect" and the "safety effect" categories of hidden failures.

The proposed method considers as-bad-as-old (ABAO) inspection and repairs (due to failures found by inspection) and as-good-as-new (AGAN) effectiveness for restoration actions. It considers inspection and repair times, and takes into account the costs associated with inspection, repair and restoration, the opportunity cost of the aircraft's lost production due to inspection and repair time (maintenance downtime), and also the cost of accidents due to the occurrence of multiple failure, in order to arrive at the applicable and most cost-effective maintenance intervals.

In this study we use analytical and graphical methods to identify the optimum maintenance intervals and to decide which check package is the most appropriate option. However, the approximations and model presented by Vaurio [9] for the FFI strategy, which were found practical to apply for aircraft application with consideration of the opportunity cost of the aircraft's lost production due to maintenance downtime. This adopted model is used for cross-checking with the results obtained by the graphical methods, and for validation in this context. Moreover, instead of the average time unavailability, which was used by Vaurio [9] for risk constraint optimization, the Mean Fractional Dead Time (MFDT) is used, which is proposed by Rausand and Vatn [12].

\section{REPAIRABLE UNITS AND PROBABILISTIC MODELS}

A repairable system is a system which, after failing to perform one or more of its functions satisfactorily, can be restored to fully satisfactory performance by any method other than replacement of the entire system [15]. The quality or effectiveness of the repair action is categorized as [15], [16], and [17]:

1) Perfect repair i.e. restoring the system to the original state, to a "like-new" condition,

2) Minimal repair, i.e. restoring the system to any "likeold" condition,

3) Normal repair, i.e. restoring the system to any condition between the conditions achieved by perfect and minimal repair.

In fact, based on the quality and effectiveness of the repair action, a repairable system may end up in one of the following five possible states after repair [15], [16], and [17]:

1) as good as new;

2) as bad as old;

3) better than old but worse than new;

4) better than new;
5) worse than old.

While perfect repair rejuvenates the unit to the original condition, i.e. to an as-good-as-new condition, minimal repair brings the unit to its previous state just before repair, i.e. an as-bad-as-old condition, and normal repair restores the unit to any condition between the conditions achieved by perfect and minimal repair, i.e. better than old but worse than new condition. However, states four and five may also happen. For example, if through a repair action a major modification takes place in the unit, it may end up in a condition better than new, and if a repair action causes some error or an incomplete repair is carried out, the unit may end up in a worse-than-old condition.

Failures occurring in repairable systems are the result of discrete events occurring over time. These situations are often called stochastic point processes [17]. The stochastic point process is used to model the reliability of repairable systems, and the analysis includes the homogeneous poisson process (HPP) renewal process (RP), and the nonhomogeneous Poisson process (NHPP).

A renewal process is a counting process where the interoccurrence times are independent and identically distributed with an arbitrary life distribution [16]. Upon failure, the component is thus replaced or restored to an asgood-as-new- condition.

The NHPP is often used to model repairable systems that are subject to a minimal repair. Typically, the number of discrete events may increase or decrease over time due to trends in the observed data. An essential condition of any homogeneous Poisson process (HPP) is that the probability of events occurring in any period is independent of what has occurred in the preceding periods. Therefore, an HPP describes a sequence of independently and identically distributed (IID) exponential random variables. Conversely, an NHPP describes a sequence of random variables that are neither independently nor identically distributed. The NHPP differs from the HPP in that the rate of occurrences of failures varies with time rather that being a constant. The renewal process as well as the NHPP are generalizations of the HPP, both having the HPP as a special case. [16]

To determine whether a process is an HPP or NHPP, one must perform a trend analysis and serial correlation test to determine whether an IID situation exists [7]. Recently the generalized renewal process (GRP) also is introduced to generalize the third point processes discussed above [16].

The failure of a component may be partial, and the repair work performed on a failed component may be imperfect. Therefore, the time periods between successive failures are not necessarily independent. This is a major source of trend in the failure rate. Furthermore, repairs made by adjusting, lubricating, or otherwise treating component parts that are wearing out provide only a small additional capability for further operation, and do not renew the component or system. These types of repair may result in a trend of increasing failure rates [17].

Experience shows that, for many of the aged repairable units, the IID assumption is contradicted in reality. Different approaches are introduced to model the probability of failure for a non-IID data set, and in the present study the power law process has been selected. The utilisation of a power 
law process to describe the data set is not contradicted. For a test of the power law process, readers are referred to [7].

In this study, minimal repair is considered, and hence the unit returns to an "as-bad-as-old" state after inspection and repair actions. On the other hand, the component keeps the state which it was in just before the failure that occurred prior to inspection and repair, and the arrival of the $i^{\text {th }}$ failure is conditional on the cumulative operating time up to the (i$1)^{\text {th }}$ failure. Under this assumption, the rate of occurrence of failure (ROCOF) of the NHPP in the power law is defined as [8], [16]:

$h(t)=\frac{\beta}{\alpha}\left(\frac{t}{\alpha}\right)^{\beta-1}$

and the cumulative ROCOF will be:

$H(t)=\left(\frac{t}{\alpha}\right)^{\beta}$

where $\alpha$ and $\beta$ denote the scale and shape parameters. Considering NHPP, the reliability and failure probability (unreliability) functions at time " $t$ " are defined as:

$R(t)=e^{-H(t)}=\left[\exp -\left(\frac{t}{\alpha}\right)^{\beta}\right]$

$F(t)=1-R(t)=1-e^{-H(t)}=1-\left[\exp -\left(\frac{t}{\alpha}\right)^{\beta}\right]$

In fact, we are interested in knowing, if the unit is tested and found functional at time $t_{1}$, what the probability of failure and survival will be at time $t_{2}$ after inspection at time $t_{1}$. Hence, the following conditional probability is defined:

$\operatorname{Pr}\left(t_{2} \mid t_{1}\right)=\frac{F\left(t_{2}\right)-F\left(t_{1}\right)}{R\left(t_{1}\right)}=1-\frac{R\left(t_{2}\right)}{R\left(t_{1}\right)}=1-\exp \left[H\left(t_{1}\right)-H\left(t_{2}\right)\right]$

On the other hand, if the component is found functional (i.e. is found to have survived) at the $(N-1)^{\text {th }}$ inspection (i.e. at $\mathrm{T}, 2 \mathrm{~T}, 3 \mathrm{~T}, \ldots \mathrm{NT}$ inspection times), the conditional probability and survival at any time, " $t$ ", within the $\mathrm{N}^{\text {th }}$ inspection cycle is given by:

$$
\begin{aligned}
& \mathrm{F}_{\mathrm{N}}(t)=1-\exp \left[\left(\frac{(N-1) T}{\alpha}\right)^{\beta}-\left(\frac{(N-1) T+t}{\alpha}\right)^{\beta}\right] \\
& \mathrm{R}_{\mathrm{N}}(t)=\exp \left[\left(\frac{(N-1) T}{\alpha}\right)^{\beta}-\left(\frac{(N-1) T+t}{\alpha}\right)^{\beta}\right]
\end{aligned}
$$

where " $t$ " denotes the local time within the $\mathrm{N}^{\text {th }}$ inspection cycle.

\section{UNAVAILABILITY CHARACTERISTICS OF REPAIRABLE UNITS SUBJECT TO HIDDEN FAILURES}

The unavailability of hidden functions is usually measured by the Mean Fractional Dead Time (MFDT), i.e. the mean proportion of time during which the proposed item is not functioning as protection or a barrier [16]. If dormant (undetected) failures occur while the system is in a non- operating state, the system availability can be influenced by the frequency at which the system is inspected. Note that inspection, cannot improve reliability, but can only improve availability [4].

According to Ebeling [4], Vaurio [9], and Rausand and Vatn [12], the availability at time " $t$ " within the $\mathrm{N}^{\text {th }}$ inspection cycle is equal to the conditional reliability i.e. $\mathrm{R}_{\mathrm{N}}(\mathrm{t})$ (see Eq. 3), and respective unavailability is corresponds to the conditional probability function i.e. $F_{N}(t)$ (see Eq. 2).

Consequently, the average unavailability within the $\mathrm{N}^{\text {th }}$ inspection cycle with inspection at every " $\mathrm{T}$ " time, i.e. $\operatorname{MFDT}_{(\mathrm{T}, \mathrm{N})}$, is given by [10], [12]:

$$
\begin{gathered}
\operatorname{MFDT}_{(\mathrm{T}, \mathrm{N})}=\frac{1}{\mathrm{~T}} \int_{(\mathrm{N}-1) \mathrm{T}}^{\mathrm{NT}} \mathrm{F}_{\mathrm{N}}(\mathrm{t}) \mathrm{dt} \\
\operatorname{MFDT}_{(\mathrm{T}, \mathrm{N})}=\frac{1}{\mathrm{~T}} \int_{(\mathrm{N}-1) \mathrm{T}}^{\mathrm{NT}} 1-\exp \left[\left(\frac{(\mathrm{N}-1) \mathrm{T}}{\alpha}\right)^{\beta}-\left(\frac{(\mathrm{N}-1) \mathrm{T}+\mathrm{t}}{\alpha}\right)^{\beta}\right] \mathrm{dt}
\end{gathered}
$$

As Rausand and Vatn [12] suggested, the conditional probability in the middle of the $\mathrm{N}^{\text {th }}$ inspection interval, i.e. $\mathrm{F}[(\mathrm{N}+0.5) \mathrm{T} \mid \mathrm{NT}]$, is a good approximation for $\mathrm{MFDT}_{(\mathrm{T}, \mathrm{N})}$ as shown below:

$\operatorname{MFDT}_{(\mathrm{T}, \mathrm{N})} \approx 1-e^{\left.-\left(\frac{T}{\alpha}\right)^{\beta\left[(N-0.5)^{\beta}-(N-1)\right.} \beta\right]}$

Fig. 1 illustrates an example of the point and average interval unavailability behaviour of a typical hidden function in a period of operating time (e.g. $5500 \mathrm{FH}$ ), when the function is tested at each "T" interval (e.g. 500FH). As is shown, when there is an aging effect, i.e. $\beta>1$, the MFDT increases in subsequent inspection cycles (see Fig. 1).

\section{PRoposed ANALYTiCAL MOdel}

Fig. 2 shows the schematic description of a maintenance

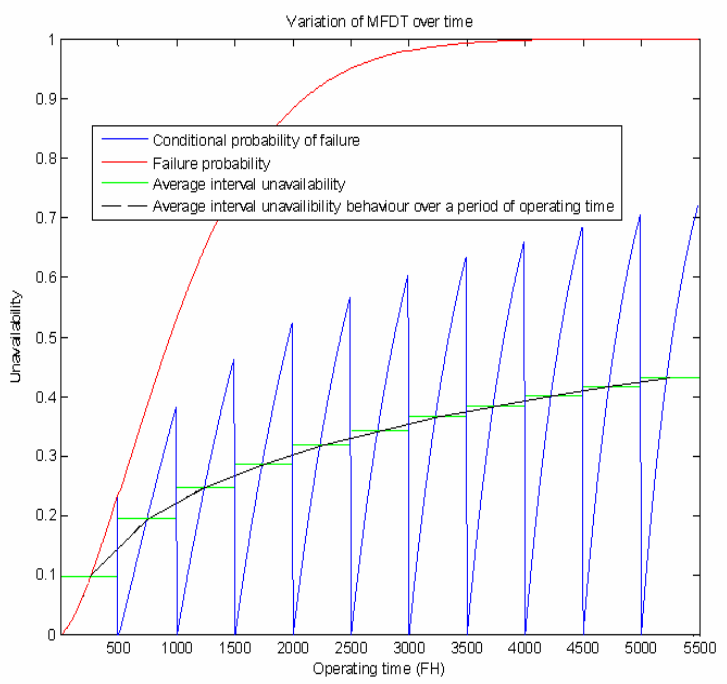

Figure 1: Variation of MFDT over time, for $\mathrm{T}=500 \mathrm{FH}, \alpha=1200$ and $\beta=1.5$ 


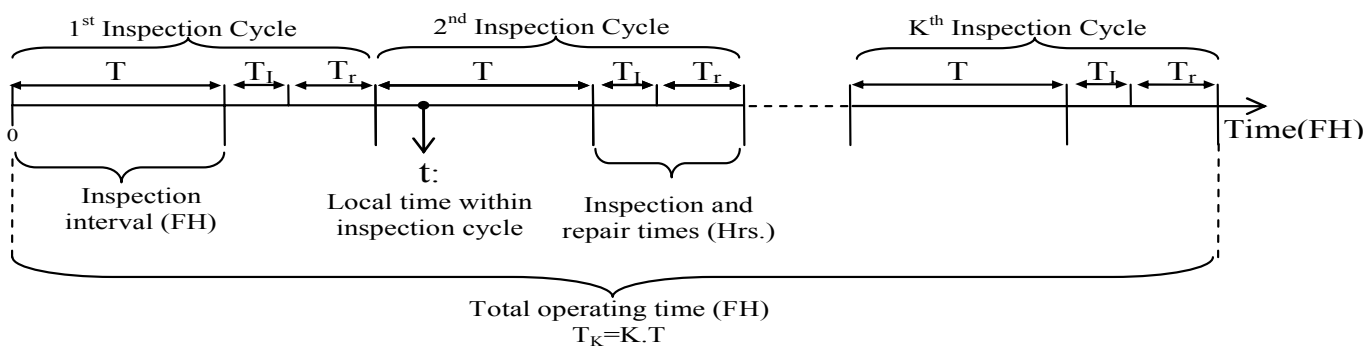

Figure 2: Schematic description of inspection cycles

event. The aircraft must be grounded to perform the inspection task after the accumulated "T" flight hours (FH). The first inspection is performed after " $\mathrm{T}$ " $\mathrm{FH}$, and consequently the $\mathrm{N}^{\text {th }}$ inspection will be performed after "N.T" operating hours. The inspection task takes $T_{I}$ hours and, in the case of a finding which leads to a repair, the repair takes $T_{\mathrm{r}}$ hours. Hence, an inspection cycle includes $\mathrm{T}$, $T_{I}$ and $T_{r}$. An expected operating time, " $T_{k}$ ", is divided into $\mathrm{K}$ inspection cycles with the interval $\mathrm{T}$, so that $\mathrm{T}_{\mathrm{k}}=\mathrm{K}$.T.

In view of an operating time of $\mathrm{T}_{\mathrm{k}}$, we are interested in identifying the optimum maintenance task interval $(\mathrm{T})$ and frequency $(\mathrm{K})$ that will minimize the cost per flight hour, for both the "non-safety effect" and the "safety effect" failure category under the following two strategies:

- $\quad$ Failure Finding Inspection (FFI),

- A combination of FFI and restoration action (FFI+Res).

The analytical model presented in this paper is based on the following assumptions:

1) The failures are not evident to the operating crew and are only detectable by inspection or demand, and hence do not interrupt the aircraft operation when they occur.

2) The function of the proposed unit is not available during the inspection and repair time.

3) The failures are completely detectable by inspection/testing.

4) The component is functional after Inspection/repair, and restoration.

5) The failures associated with normal operation of the aircraft are considered in the unavailability and cost model. Inspection, repair, and restoration actions do not create failure by the nature of the tasks themselves and through the maintenance crew. Common-cause failures, due to design and manufacturing, or caused during a demand on system (initiating events), are not considered.

A common practice in aviation is to identify the maintenance tasks' cost per operating flight hour. The following cost parameters are considered for cost modelling:

1) Direct cost of inspection task, $C_{i}$. This is considered as a deterministic value and constant in consecutive inspection cycles.

2) Direct cost of possible repair due to a finding, $C_{r}$. As the system is undergoing aging, the probability of failure will change in consecutive inspection cycles. Hence, the expected repair cost within the $\mathrm{N}^{\text {th }}$ inspection cycle can be estimated as $C_{r} \cdot \mathrm{F}_{\mathrm{N}}(T)$.
3) Cost of restoration, $C_{\text {Res. }}$. This is a constant and deterministic value which includes the direct cost of restoration and the respective indirect costs of shipping, man-hours, etc.

4) Cost of an accident, due to multiple failures, $C_{A}$. The expected value of $C_{A}$ in the $\mathrm{N}^{\text {th }}$ inspection cycle depends on the expected time during which the function is not available between two inspections, "MFDT $\mathrm{T}_{(\mathrm{T}, \mathrm{N})} \cdot \mathrm{T}$ ", and the probability of demand, $\varphi$, i.e. "C $\mathrm{C}_{\mathrm{A}} \cdot \varphi \cdot \mathrm{MFDT}_{(\mathrm{T}, \mathrm{N})} \cdot \mathrm{T}$ ". For the "safety effect" category of hidden failure, $\mathrm{C}_{\mathrm{A}}$ refers to the cost of accidents, e.g. the possible loss of the equipment and/or its occupants, while for the "non-safety effect" category, $\mathrm{C}_{\mathrm{A}}$ refers to the cost of undesired consequences of failure, e.g. a higher maintenance cost or secondary damage to the equipment, due to the occurrence of a multiple failure.

5) Opportunity cost of the aircraft's lost production, $C_{o c}$. This cost is associated with the total aircraft downtime due to inspection and repair, i.e. $\mathrm{T}_{\mathrm{i}}$ and $\mathrm{T}_{\mathrm{r}}$ (constant values). As $F_{N}(T)$ changes in consecutive inspection cycles, the expected value of the opportunity cost of the aircraft's lost production can be estimated as $C_{o c} \cdot\left[T_{i}+T_{r} \cdot \mathrm{F}_{\mathrm{N}}(T)\right] \cdot$

Summing up, CRF for the $\mathrm{N}^{\text {th }}$ inspection cycle under the FFI strategy can be expressed as:

$C R F_{N}=\frac{C_{i}+C_{r} \cdot F_{N}(T)+C_{O c} \cdot\left[T_{i}+T_{r} \cdot F_{N}(T)\right]+\left\lfloor C_{A} \cdot \varphi \cdot \mathrm{MFDT}_{(\mathrm{T}, \mathrm{N})} \cdot T\right]}{T}$

Consequently, the CRF for " $\mathrm{K}$ " series of inspection cycles and performing one restoration at $\mathrm{T}_{\mathrm{K}}$ can be estimated as:

$\left.\mathrm{CRF}_{(\mathrm{T}, \mathrm{K}}\right)=\frac{\mathrm{C}_{\mathrm{i}}}{\mathrm{T}}+\frac{\mathrm{C}_{\mathrm{r}}}{\mathrm{KT}} \sum_{\mathrm{N}=1}^{\mathrm{K}} \mathrm{F}_{\mathrm{N}}(\mathrm{T})+\frac{\mathrm{C}_{\mathrm{oc}} \mathrm{T}_{\mathrm{i}}}{\mathrm{T}}+\frac{\mathrm{C}_{\mathrm{oc}} \mathrm{T}_{\mathrm{r}}}{\mathrm{KT}} \cdot \sum_{\mathrm{N}=1}^{\mathrm{K}} \mathrm{F}_{\mathrm{N}}(\mathrm{T})+\frac{\mathrm{C}_{\mathrm{A}} \cdot \varphi \cdot \mathrm{T}}{\mathrm{KT}} \cdot \sum_{\mathrm{N}=1}^{\mathrm{K}} \mathrm{MFD}(\mathrm{T}, \mathrm{N})+\frac{C_{\mathrm{Res}}}{K T}$

\section{A. Limiting values}

If the number of inspections tends to infinity $(\mathrm{K} \rightarrow \infty)$, then the following value for CRF can be expected: 


$$
\begin{aligned}
& \operatorname{Lim} \operatorname{CRF}_{K \rightarrow \infty}(\mathrm{T}, \mathrm{K})=
\end{aligned}
$$

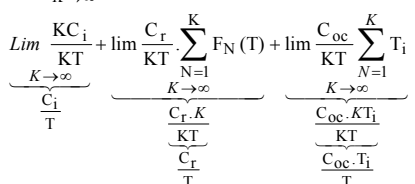

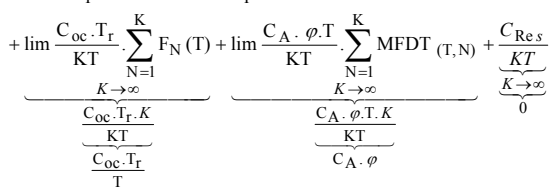

$$
\begin{aligned}
& \underset{K \rightarrow \infty}{\operatorname{Lim} \operatorname{CRF}_{(T, K)}}=\frac{\mathrm{C}_{\mathrm{i}}+\mathrm{C}_{\mathrm{r}}+\mathrm{C}_{\mathrm{oc}} \cdot\left(\mathrm{T}_{\mathrm{i}}+\mathrm{T}_{\mathrm{r}}\right)}{\mathrm{T}}+\mathrm{C}_{\mathrm{A}} \cdot \varphi
\end{aligned}
$$

The Microsoft ExcelTM software is used to enable variation of the parameters of Eq. 8, to identify the cost per unit of time for different values of $\mathrm{T}$ and $\mathrm{K}$.

Fig. 3 and 4 show CRF (the cost per unit of time) versus a large number of inspections (i.e. $\mathrm{K}$ from 1 to 1000) for different values of $\mathrm{T}$, under the FFI and FFI+Res strategies, and based on the arbitrary values of reliability and cost parameters mentioned in the figures. The following results can be concluded, which conform to Eq. 8 and 9:

1) When there is aging and when the FFI strategy is used, it is evident that CRF is an increasing function of the number of inspection cycles, i.e. as $\mathrm{K}$ increases, $\mathrm{CRF}$ will increase.

2) Moreover, comparing Fig. 3 and 4, it is evident that under the FFI+Res strategy, there are always a specific $\mathrm{K}$ and a specific $\mathrm{T}$ that result in an absolute minimum value of CRF.

3) It is evident from the figures that for all the values of

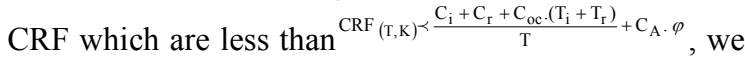
can always find values for $\mathrm{T}$ and $\mathrm{K}$.

4) It is obvious that for FFI+Res strategy, when restoration action threshold tends to infinity, i.e. $(\mathrm{K} \rightarrow \infty)$, the limit CRF does not depend on $\mathrm{C}_{\text {Res }}$.

5) When there are no undesired consequences, i.e. $C_{A} \cdot \varphi=0$, in the long run, the limit CRF tends to a value of $\frac{C_{i}+C_{r}+C_{o c} \cdot\left(T_{i}+T_{r}\right)}{T}$. For example, in Fig. 3 and 4, for $\mathrm{T}=1000$, at $\mathrm{K}=1000$ (i.e. $\mathrm{T} . \mathrm{K}=1000000 \mathrm{FH}$ ), the $\mathrm{CRF}$ will be equal to $\$ 0.19722$, which is very close to the corresponding "Lim CRF", i.e. \$0.2, that is obtained from Eq. 9.

6) When the inspection interval tends to infinity $(T \rightarrow \infty)$, then the CRF limit will be equal to the cost of an accident, i.e. " $\mathrm{C}_{\mathrm{A}} \cdot \varphi$ ".

An important conclusion is that the selection of values that result in the absolute minimum will decrease the CRF dramatically for the long-term operation of fleets of aircraft, as shown in Fig. 4.

\section{B. Optimum interval}

As seen in Fig. 3, for each number of inspection cycles, "K", there will be an inspection interval, "T", which may minimize the cost per unit of time.

However, to find the optimal inspection interval, a practical approach is to identify the CRF for different values

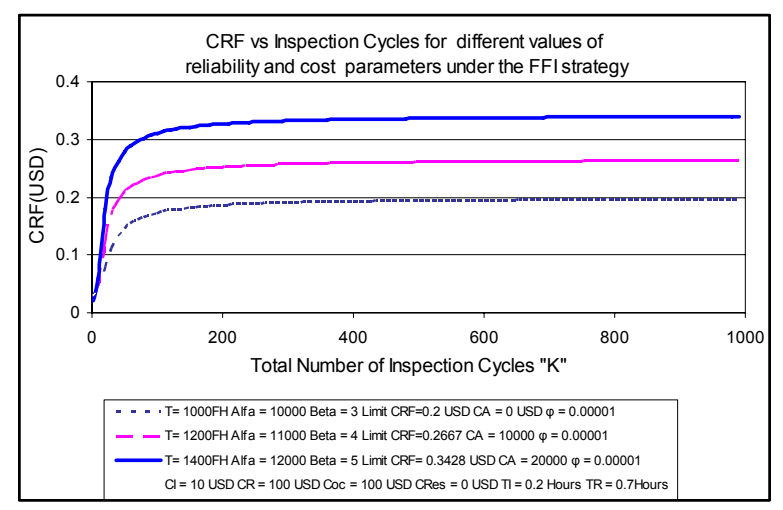

Figure 3: Cost per unit of time versus total number of inspection cycles under the Failure Finding Inspection strategy.

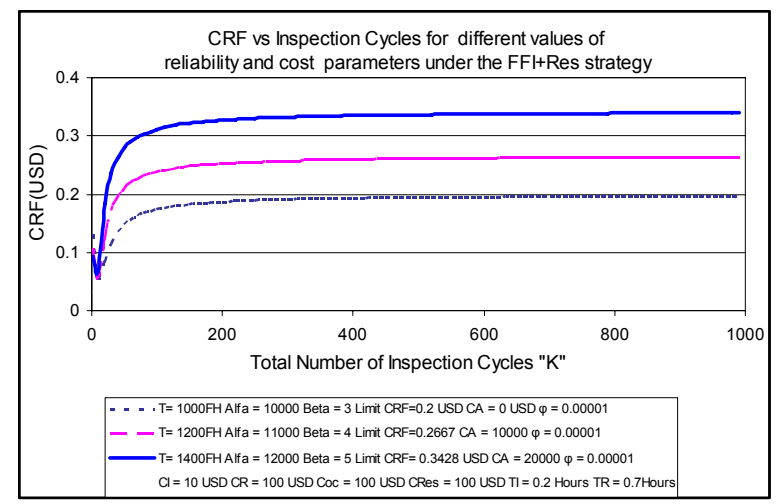

Figure 4: Cost per unit of time versus total number of inspection cycles using a combination of the Failure Finding Inspection and restoration strategies.

of $\mathrm{T}$ versus the operating time, $\mathrm{T}_{\mathrm{K}}$, which we are considering as the unit life. Then, considering an expected operating time, " $\mathrm{T}_{\mathrm{K}}$ " (e.g. 20000FH), for the unit, it is possible to compare the CRF associated with different $\mathrm{T}$ values, and to select the optimal $\mathrm{T}$ among the results.

Some adjustment is needed for Eq. 8, so that CRF can be derived as a function of the inspection interval " $\mathrm{T}$ " and the operating time " $\mathrm{T}_{\mathrm{k}}$ " as follows:

1) In fact, the operating time " $T_{k}$ " is divided into $K$ inspections with the interval $\mathrm{T}$, so that $\mathrm{T}_{\mathrm{k}}=\mathrm{K}$.T.

2) The following equations are valid under certain conditions for $\mathrm{F}_{\mathrm{N}}(\mathrm{T})$, as proved by Vaurio [9]:

$\sum_{N=0}^{K} F_{N}(T) \cong H\left(T_{K}\right)$

$\sum_{N=0}^{K} \overline{F_{N}(T)}=\sum_{N=0}^{K} M F D T_{(T, N)} \cong H\left(T_{K}\right) / 2$

Where $F_{N}(T)$ represents the conditional probability of having just one failure in the $\mathrm{N}^{\text {th }}$ inspection interval, provided that the component found functional at $(\mathrm{N}-1)^{\text {th }}$ inspection. $\mathrm{H}\left(\mathrm{T}_{\mathrm{K}}\right)$ represents the mean number of failures over an interval of $\left(0, \mathrm{~T}_{\mathrm{K}}\right)$. Hence, it is evident that $\mathrm{H}\left(\mathrm{T}_{\mathrm{K}}\right)$ overestimates $\Sigma F_{N}(T)$. However, this overestimation can be acceptable if it is rational. Fig. $5 \mathrm{a}$ and $5 \mathrm{~b}$ show values of $H\left(T_{K}\right)$ and $\Sigma F_{N}(T)$ for different values of " $T$ " and $T_{K}$, for 
comparison, considering the arbitrary values of $\alpha=10000$

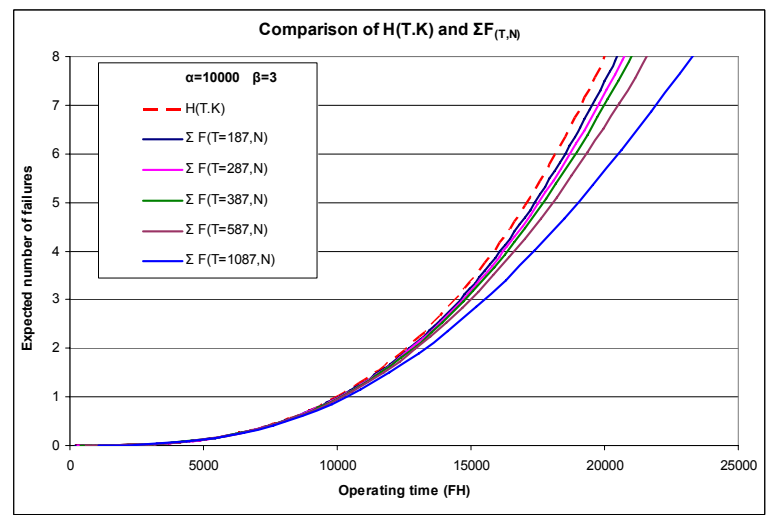

Figure 5a: Comparison of $\mathrm{H}\left(\mathrm{T}_{\mathrm{K}}\right)$ and $\sum_{N=0}^{K} F_{N}(T)$

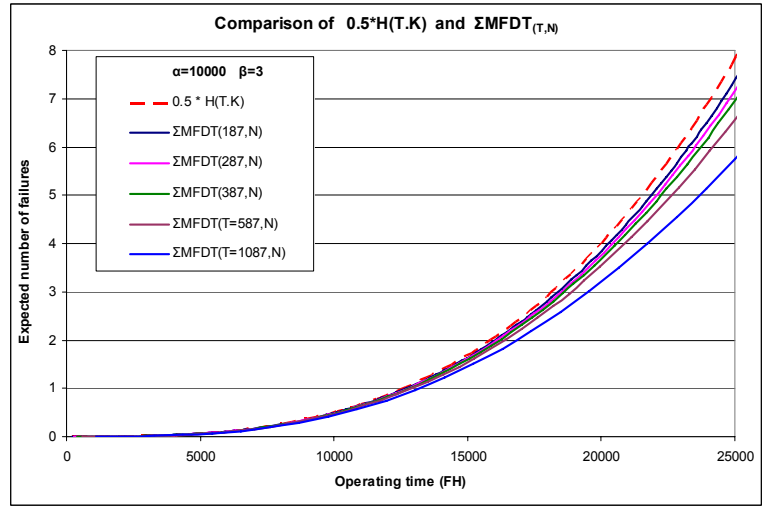

Figure $5 \mathrm{~b}$ : Comparison of $0.5 \mathrm{H}\left(\mathrm{T}_{\mathrm{K}}\right)$ and

$$
\sum_{N=0}^{K} M F D T_{(T, N)}
$$

and $\beta=3$. As is shown in the figures, up to $T_{K}=10000 \mathrm{FH}$ (the operating time), the estimation is fairly good, but afterwards the deviation is visible even in the graph. It should be noted that this estimation depends on the value of $\alpha$ and $\beta$. For larger $\alpha$ and smaller $\beta$ values, the $H\left(T_{K}\right)$ and $F_{N}(T)$ become more close and tend to lead to more accuracy in the estimation, while smaller $\alpha$ and larger $\beta$ values tend to lead to more deviation in the estimation. Moreover, selecting larger $\mathrm{T}$ values increases the inaccuracy in the estimation.

Likewise, using the method introduced by Vaurio [9], by substituting Eq. 10 and 11 into Eq. 8, and denoting T.K as $\mathrm{T}_{\mathrm{K}}$, the following CRF can be derived as a function of the inspection interval " $\mathrm{T}$ " and the operating time " $\mathrm{T}_{\mathrm{k}}$ ":

$C R F_{(T, K)}=\frac{C_{i}}{T}+\frac{C_{r \cdot H\left(T_{K}\right)}}{T_{K}}+\frac{C_{o c} T_{i}}{T}+\frac{C_{o c} T_{r} \cdot H\left(T_{K}\right)}{T_{K}}+\frac{C_{A} \cdot \varphi \cdot T \cdot H\left(T_{K}\right)}{2 T_{K}}+\frac{C_{\mathrm{Res}}}{T_{K}}(12)$

The optimum inspection interval, $\mathrm{T}_{\mathrm{OP}}$, that can minimize the $\mathrm{CRF}$, by a fixed operating time, $\mathrm{T}_{\mathrm{K}}(\mathrm{FH})$, can be found through this derivative: $\frac{\left(C R F_{(T, K)}\right)}{d T}=0$

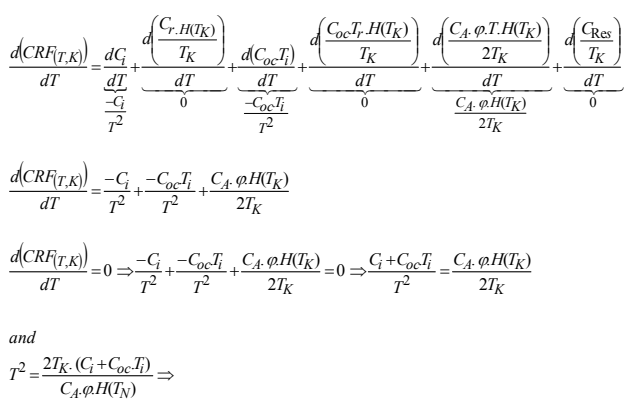

This leads to:

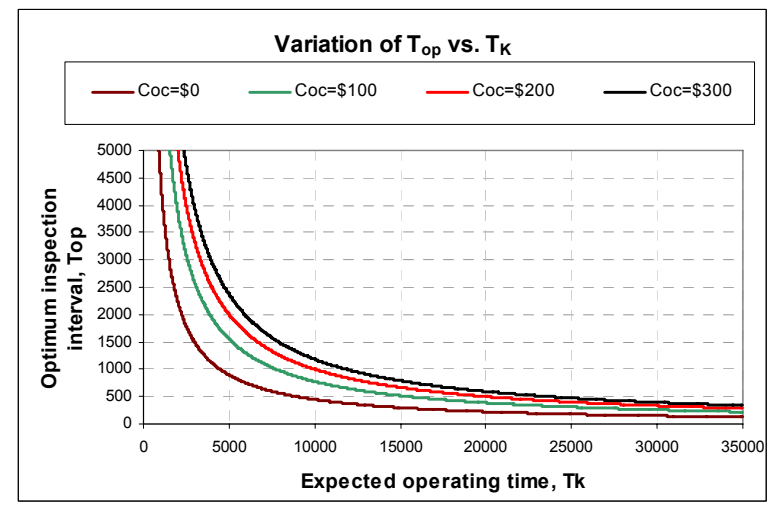

Figure 5c: Comparison of $\mathrm{T}_{\mathrm{op}}$ versus the operating time for different values of $\mathrm{C}_{\mathrm{oc}}$.

$$
T_{o p}=\left[\frac{2 T_{K} \cdot\left(C_{i}+C_{o c} \cdot T_{i}\right)}{C_{A} \cdot \varphi \cdot H\left(T_{K}\right)}\right]^{1 / 2}
$$

It is obvious that $\mathrm{T}_{\text {op }}$ does not depend on $\mathrm{C}_{\text {Res }}$, because considering a fixed $T_{K}$ value means that we will perform the restoration task at $T_{K}$ and this does not change the order of the optimal intervals for both the FFI and the FFI+Res strategies. Moreover, by increasing $T_{K}$ the optimum inspection interval, $T_{\text {op }}$, decreases, as $H\left(T_{K}\right)$ changes faster than $T_{K}$, and by decreasing $T_{K}, T_{O P}$ increases. It is also obvious that, for any specific values of $\mathrm{T}_{\mathrm{K}}$, there will be an inspection interval, " $T$ ", that will minimize the cost per unit of time for a specific operating time, $\mathrm{T}_{\mathrm{K}}$. It is also evident that, as $\mathrm{C}_{\mathrm{i}}, \mathrm{C}_{\mathrm{oc}}$ or $\mathrm{T}_{\mathrm{i}}$ increases, $\mathrm{T}_{\mathrm{op}}$ tends to increase, meaning that the aircraft will have less ground time (see Fig. 5c).

\section{TASK INTERVAL SELECTION FOR THE "NON-SAFETY EFFECT" CATEGORY OF HIDDEN FAILURE}

In the case of the "non-safety effect" category of failure, MSG-3 [5] requires the introduction of a task to assure the availability of the hidden function necessary to avoid the economic consequences of multiple failures. It must also be cost-effective, meaning that the cost of the maintenance task should be less than the economic effect of the multiple failures.

\section{A. FFI strategy for the "non-safety effect" category}

Setting $\mathrm{C}_{\text {Res }}=0$ in Eq. 12, leads to the $\mathrm{CRF}_{(\mathrm{T}, \mathrm{K})}$ for the FFI strategy only. 


$$
C R F_{(T, K)}=\frac{C_{i}}{T}+\frac{C_{r \cdot H\left(T_{K}\right)}}{T_{K}}+\frac{C_{o c} T_{i}}{T}+\frac{C_{o c} T_{r} \cdot H\left(T_{K}\right)}{T_{K}}+\frac{C_{A} \cdot \varphi \cdot T \cdot H\left(T_{K}\right)}{2 T_{K}}
$$

As the unit is undergoing aging $(\beta>1)$, by increasing $T_{K}$ the $H\left(T_{K}\right)$ changes faster than $T_{K}$, hence the CRF under the FFI strategy is an increasing function of $T_{K}$, meaning that by increasing the operating time, CRF will increase.

In accordance with Eq. 13 and considering a target operating time of $T_{K}=20000 \mathrm{FH}$, with the selected values of $\alpha=10000, \beta=3, C_{A} . \varphi=1, C_{i}=10, C_{R}=100, C_{O C}=100, T_{i}=0.2$ and $\mathrm{T}_{\mathrm{r}}=0.7$, the optimum inspection interval will be estimated to " $\mathrm{T}_{\mathrm{op}}=387 \mathrm{FH}$ ", which leads to $\mathrm{CRF}=\$ 0.209$ with $\mathrm{K}=52$ [20000/387=51.67].

In Fig. 6a, $\mathrm{K}$ and $\mathrm{T}$ in Eq. 14 have been changed to illustrate the variation of CRF versus the operating time, $\mathrm{T}_{\mathrm{K}}$, for different values of the inspection interval $\mathrm{T}$, based on the arbitrary values used in previous example. Fig. $6 \mathrm{~b}$ also shows the respective CRF of different inspection intervals shown in Fig. 6a, considering $\mathrm{T}_{\mathrm{K}}=20000 \mathrm{FH}$. As is shown, for an operating time of $\mathrm{T}_{\mathrm{K}}=20000 \mathrm{FH}$ and the above selected values, the optimum inspection interval is " $\mathrm{T}_{\mathrm{op}}=450 \mathrm{FH}$ ", which leads to $\mathrm{CRF}=\$ 0.2042$ with $\mathrm{K}=44$ $[20000 / 450=44.44]$. The difference between the result obtained from Eq. 13 and that obtained from the graphical method is due to the overestimation of $\mathrm{H}\left(\mathrm{T}_{\mathrm{K}}\right)$ in Eq. 13, which was discussed in the previous section. However, as Fig. $6 \mathrm{~b}$ shows, the CRF is not sensitive around absolute $\mathrm{T}_{\mathrm{op}}$ (i.e. $450 \mathrm{FH}$ ), meaning that a range of inspection intervals, i.e. $\mathrm{T}_{\mathrm{op}} \varepsilon[350 \mathrm{FH}-600 \mathrm{FH}]$, is reasonably acceptable. Hence, the result obtained from Eq. 13 is quite satisfactory in a sense that it helps us to find the area of optimum inspection

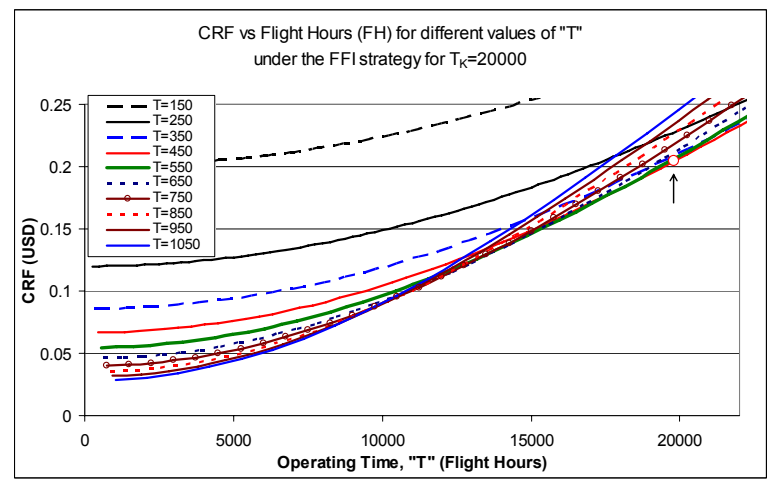

Figure 6a: Cost per unit of time versus total flight hours under the Failure Finding Inspection strategy.

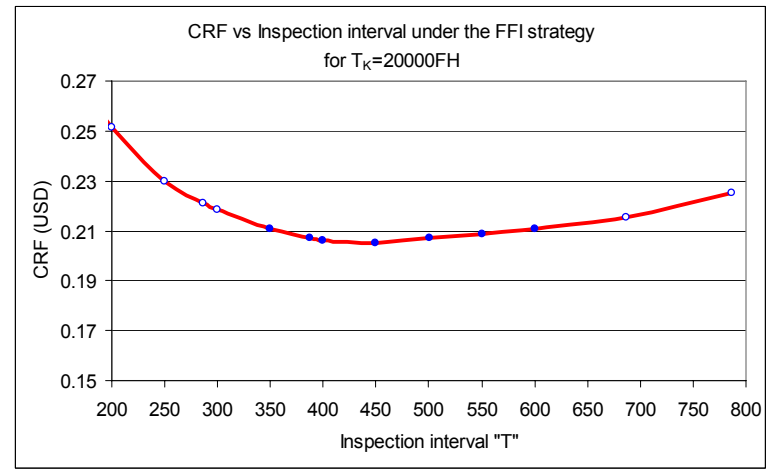

Figure 6b: Cost rate versus inspection interval for $T_{K}=20000$ under the Failure Finding Inspection strategy. intervals.

In fact, the properties of $\mathrm{T}_{\mathrm{op}} \varepsilon$ [350FH-600FH] help us to decide which check package (e.g. $\mathrm{A}_{1}=250 \mathrm{FH}, \mathrm{A}_{2}=500 \mathrm{FH}$, $\mathrm{B}=1000 \mathrm{FH}, \quad \mathrm{C}=5000 \mathrm{FH}, \quad$ or $\mathrm{D}=10000 \mathrm{FH}) \quad$ is more appropriate for inclusion of the inspection and restoration tasks in the check. As these tasks will be performed along with the other tasks included in the check package, the related assigned downtime will be reduced, which will also reduce the cost associated with the maintenance downtime and will ultimately reduce the CRF more.

Summing up, since the results show that the cost rate of performing FFI is less than the economic effect of failure, i.e. $\varphi \cdot C_{A}=1 \mathrm{USD}$, the performance of this task is effective. Moreover, in accordance with the range of $\mathrm{T}_{\text {op }} \varepsilon[350 \mathrm{FH}-$ $600 \mathrm{FH}]$, including the task in the $A_{2}$ check package is reasonable; hence, the following task will be selected:

- Performing an inspection at every $\mathrm{A}_{2}$ check, i.e. " $\mathrm{T}=500 \mathrm{FH} "$.

\section{B. FFI+Res strategy for the "non-safety effect" category}

Setting the value for $\mathrm{C}_{\mathrm{Res}}$ in Eq. 12 leads to the identification of $\mathrm{CRF}_{(\mathrm{T}, \mathrm{K})}$ under the FFI+Res strategy. This gives the optimum inspection interval in a situation where we perform $\mathrm{K}$ inspections and carry out one restoration at $T_{K}$. In trade-off analysis it is of interest to identify which combination of the inspection interval, $\mathrm{T}$, and the numbers of inspection, $\mathrm{K}$, generates the lowest $\mathrm{CRF}$ among all the combinations of $\mathrm{T}$ and $\mathrm{N}$.

In order to find the most optimum combination of $\mathrm{T}$ and $\mathrm{K}$, which generates the absolute minimum CRF, a joint optimization based on both $\mathrm{T}$ and $\mathrm{T}_{\mathrm{K}}$ is needed. However, in order to simplify the task analysis process, we prefer to apply a graphical method to identify the most optimized combination of $\mathrm{T}$ and $\mathrm{K}$.

Fig. 7 shows the variation of CRF with the different numbers of inspections, $\mathrm{K}$, for different $\mathrm{T}$ values, based on the arbitrary values used in the previous section and considering $\mathrm{C}_{\mathrm{Res}}=\$ 1000$. Likewise, Fig. 8 also shows CRF versus inspection intervals, $\mathrm{T}$, for different numbers of inspection cycles. According to the figures, it is evident that, for any selected value of $T$, there are specific numbers of inspections, $\mathrm{K}$, which in combination with a restoration task lead to a minimized CRF. However, as is shown, there are also combination of $\mathrm{T}$ and $\mathrm{K}$ that generate an absolute minimized CRF under the FFI+Res strategy. As shown in Fig 7, it is obvious that the CRF is not sensitive around the absolute optimum $\mathrm{K}$.

Fig. 9 also shows the variation of CRF versus the operating time " $\mathrm{T}_{\mathrm{K}}$ " for different inspection intervals, $\mathrm{T}$, based on the arbitrary values used in the previous figures. According to the figures, selecting $\mathrm{T}=950 \mathrm{FH}$ and a restoration after 10 inspections, i.e. at $\mathrm{T}_{\mathrm{K}}=9500 \mathrm{FH}$, leads to $\mathrm{CRF}=\$ 0.1893$.

Fig. 10 shows the optimum values of CRF obtained from Fig. 8 versus the respective $T$ values. As the figure shows, the CRF is not sensitive around $T_{\text {op }}$. This means that, for planning purposes and task packaging, a range of $\mathrm{T}_{\text {op }} \varepsilon$ [700FH-1150FH] with the respective values of $\mathrm{K}$ can be considered when deciding which check package (e.g. $\mathrm{A}_{1}=250 \mathrm{FH}, \quad \mathrm{A}_{2}=500 \mathrm{FH}, \quad \mathrm{B}=1000 \mathrm{FH}, \quad \mathrm{C}=5000 \mathrm{FH}, \quad$ or $\mathrm{D}=10000 \mathrm{FH})$ is more appropriate for inclusion of the 


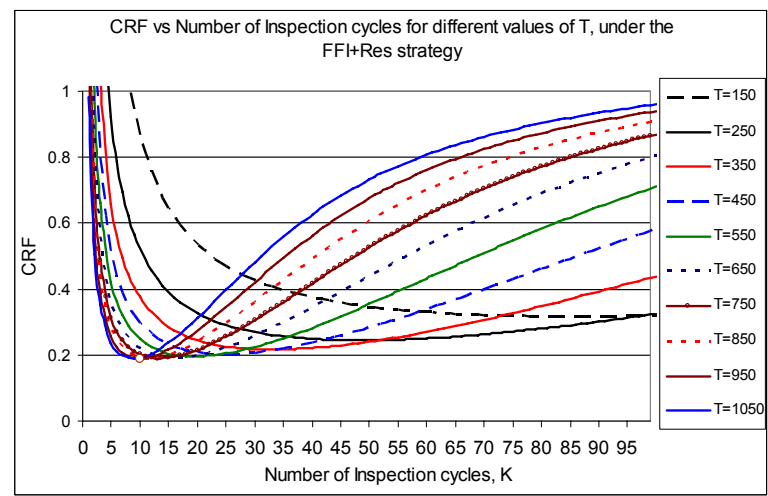

Figure 7: Cost rate function versus number of inspection interval under the FFI+Res strategy.

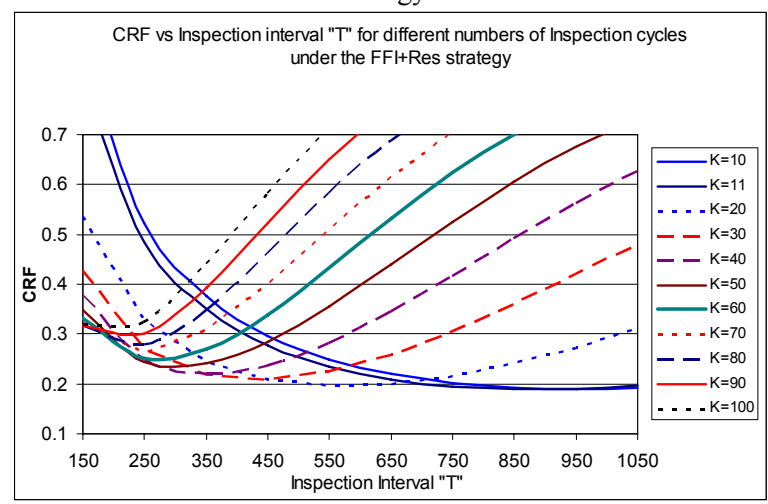

Figure 8: Cost rate function versus inspection intervals under FFI+Res the strategy.

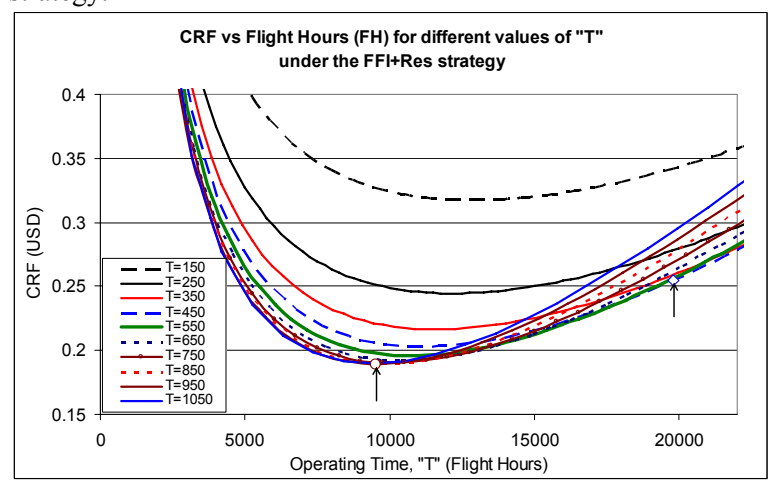

Figure.9: Cost per unit of time versus total flight hours under the FFI+ Res strategy.

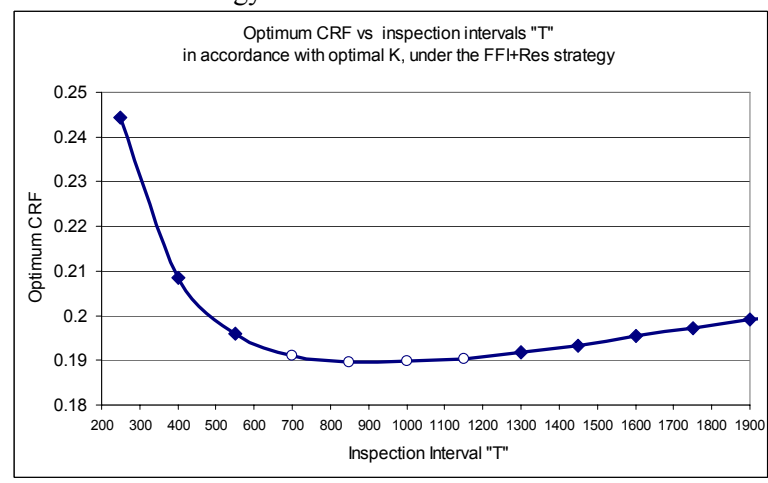

Figure 10: Cost rate versus optimum inspection interval under the FFI+Res strategy.

inspection and restoration tasks. Table I shows the candidate options which are more appropriate in accordance with the check package options.

Summing up, the results gained under the FFI and FFI+Res strategies show that the cost rate of performing both strategies is less than the economic effect of failure, i.e. $\varphi . \mathrm{C}_{\mathrm{A}}=1 \mathrm{USD}$. Moreover, Option 5 is suitable for inclusion of the inspection task in the $B$ check package and the restoration task in the $\mathrm{D}$ check package, as increasing the number of inspections by "1" does not affect CRF (see Fig. 8). Hence, the following tasks will be selected:

1) Performing an inspection at every $B$ check, i.e. "T=1000FH" and,

2) Performing a restoration task at the $D$ check, i.e. "T $=10000 \mathrm{FH}$ ".

In fact, at the D check, the unit will be restored and the function will return to an as-good-as-new condition. However, the following issues should be considered in decision making:

1) The cost of holding a spare part for replacement and the possible cost for the unavailability of spares during inspection.

2) The possibility of performing restoration in-house and the investment cost involved.

Comparing all strategies, if the economic penalties are still high, then redesign may be considered as an option in cost-effectiveness analysis, to reduce or avoid the probability of multiple failures. The options for redesign may include the incorporation of alerting or warning devices, to make the failure evident to the operating crew, the inclusion of built-in tests or automated test capability to reduce the maintenance downtime, increasing the redundancy level, or incorporating some prognostic health management into the unit or the whole system.

Table I: Options for task selection.

\begin{tabular}{|l|l|l|l|l|l|}
\cline { 2 - 6 } \multicolumn{1}{c|}{} & \multicolumn{5}{c|}{ Options } \\
\cline { 2 - 6 } \multicolumn{1}{c|}{} & 1 & 2 & 3 & 4 & 5 \\
\hline Inspection Interval "T" & 700 & 800 & 900 & 950 & 1000 \\
\hline Optimum K & 15 & 12 & 11 & 10 & 9 \\
\hline Restoration Time & 10500 & 9600 & 9900 & 9500 & 9000 \\
\hline CRF & 0.1910 & 0.1998 & 0.1893 & 0.1893 & 0.1898 \\
\hline
\end{tabular}

\section{TASK INTERVAL SELECTION FOR THE "SAFETY EFFECT" CATEGORY OF HIDDEN FAILURE: A RISK-CONSTRAINED OPTIMIZATION}

In the case of the "safety effect" category of failure, MSG-3 requires the introduction of a task to limit the probability of multiple failures, i.e. the task must ensure adequate availability of the hidden function to reduce the risk of a multiple failure. Moreover, the policies of Civil Aviation Authorities or airlines may set additional conditions to limit the risk of failure which applies further than cost consideration.

For example, major failure conditions must be no more frequent than improbable (remote) failure conditions to each airplane during its total life. Improbable (remote) failure conditions are those having a probability which is in the order of $1 \times 10^{-5}$ or less, but which is greater than $1 \times 10^{-7}[18]$.

The acceptable risk problem should be solved by combining the acceptance criteria with the so-called ALARP (as-low-as-reasonably-practicable) principle. The idea here is that the company should define values for unacceptable probabilities of certain undesired events. To verify ALARP, 
different tools are being used, including cost-benefit analysis and cost-effectiveness analysis [12], [19].

Hence, risk analysis is needed to reveal whether the risk of failure is below the specified limit by using a selected inspection interval, " $\mathrm{T}$ ". Considering $\mathrm{R}_{\max }$ as the maximum allowable limit for the probability of multiple failures, then the optimization process needs to minimize the cost rate function under the following supplementary constraint:

$$
\begin{gathered}
\varphi . M F D T_{(T, N=K)} \leq \mathrm{R}_{\max } \Rightarrow \operatorname{MFDT}_{(T, N=K)} \\
\text { Hence, } 1-e^{-\left(\frac{T}{\alpha}\right)^{\beta}\left[(K-0.5)^{\beta}-(K-1)^{\beta}\right]} \leq \mathrm{R}_{\max } / \varphi
\end{gathered}
$$

Therefore, one needs to verify $\mathrm{T}$ that satisfies Eq. 15 for any candidate values of $\varphi, \mathrm{R}_{\max }$, and the expected operating time $\mathrm{T}_{\mathrm{K}}$ (e.g. 20000FH). Considering a specific operating time $\mathrm{T}_{\mathrm{K}}$ (e.g. $20000 \mathrm{FH}$ ), one needs to verify values for $\mathrm{T}$ and $\mathrm{K}$ that satisfy Eq. 15, for any candidate values of $\varphi, R_{\max }$.

Fig. 11 shows the variation of MFDT over time, for different values of $\mathrm{T}$, with $\mathrm{MFDT}_{\max }=0.15$. As is shown, if the unit is expected to be operated for example $\mathrm{T}_{\mathrm{K}}=20000 \mathrm{FH}$, different combination of $\mathrm{T}$ and $\mathrm{K}$, can be selected which satisfies $\mathrm{MFDT}_{\max }$ (e.g. $\mathrm{T}=150, \mathrm{~K}=133$; $\mathrm{T}=250$ and $\mathrm{K}=80 ; \mathrm{T}=270$ and $\mathrm{K}=74$ ). However, in interval selection, the combination, which generates the lowest CRF should be selected.

\section{A. FFI strategy for the "safety effect" category}

Assuming a maximum limit for MFDT, the objective is to identify values for $\mathrm{T}$ and $\mathrm{K}$, which generates the lowest possible CRF that satisfies $(M F D T)_{\max }$, if the unit is going to be used for an expected operating time $\mathrm{T}_{\mathrm{K}}$ (e.g. 20000FH).

Fig. 12 shows the CRF and the average interval unavailability behaviour (MFDT) versus operating time $T_{K}$, for different values of $\mathrm{T}$, based on the arbitrary values selected for Fig. 6, in which MFDT max $_{\text {ax }}$ is set to 0.15 .

It is obvious that the MFDT for $\mathrm{T}=450 \mathrm{FH}$, which was selected for the "non-safety effect" category, exceeds the $\mathrm{MFDT}_{\text {max }}$ after $\mathrm{T}_{\mathrm{K}}=15750 \mathrm{FH}$, i.e. after the $35^{\text {th }}$ inspection, and the risk of multiple failure will then be higher than the allowable limit, meaning that $\mathrm{T}=450$ is applicable only up to $15750 \mathrm{FH}$. Hence, one needs to reduce $\mathrm{T}$ so much that the MFDT at $T_{K}=20000 \mathrm{FH}$ does not exceed the value $\mathrm{MFDT}_{\max }=0.15$.

As Fig. 12 shows, selecting $\mathrm{T}=270 \mathrm{FH}$ follows the $\mathrm{MFDT}_{\max }=0.15$ limitation by $\mathrm{T}_{\mathrm{K}}=20000 \mathrm{FH}$. In fact, this is the maximum inspection interval that we can use if the $\mathrm{MFDT}_{\text {max }}$ is to be followed. Following Fig. 12 and 6, it is evident that the $\mathrm{CRF}$ for $\mathrm{T}=270 \mathrm{FH}$ will be higher than that for $\mathrm{T}=450$, but this is the lowest $\mathrm{CRF}$ which can be obtained under the FFI strategy and with the MFDT $_{\max }=0.15$ constraint.

It should be noted that any extra reduction of the inspection interval, which would lead to unavailability below $(M F D T)_{\max }$, would lead to an increase in CRF. However, according to Fig. 12, changing the inspection interval to $\mathrm{T}=250$, instead of $\mathrm{T}=270$, makes it possible to include the inspection task in the $A_{1}$ check package. In this case, the amount of increase in CRF is reasonable, as the task will be performed along with other tasks included in the check package, and this itself will reduce the associated cost of downtime. Hence, the following task will be selected:

- Performing an inspection at every $\mathrm{A}_{1}$ check, i.e. "T=250FH".

\section{B. FFI+Res strategy for the "safety effect" category}

If under the FFI strategy, it is not possible to define a task that satisfies the risk limit or, the CRF is still higher than the acceptable level, by defined task, then it is necessary to take action to reduce the risk of multiple failure or cost per unit of time, below the allowable level. The next step is to

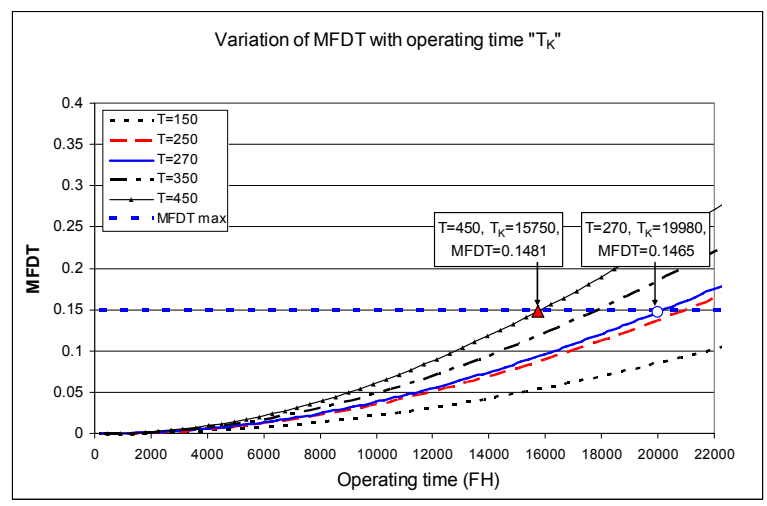

Figure 11: Mean Fractional Dead Time versus operating time for different inspection intervals.

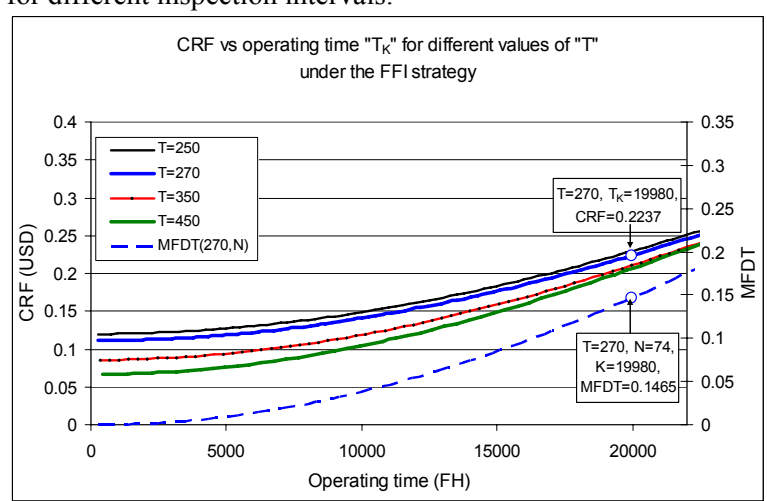

Figure.12: Comparison of cost rate function with MFDT for different $T$ values, under the FFI strategy.

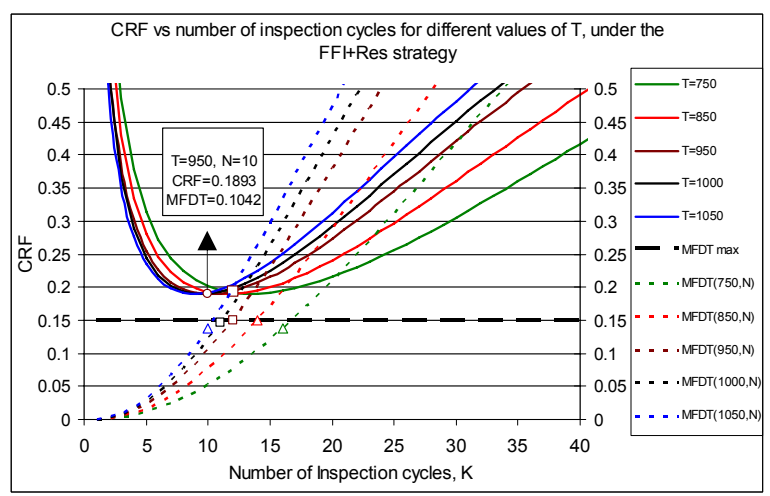

Figure 13: Comparison of cost rate function versus MFDT for different $T$ values, under the FFI+Res strategy. 
evaluate whether the FFI+Res strategy is effective option.

The same rule and discussion are applicable to the FFI+Res strategy as are applicable to the FFI strategy, to verify Eq. 15 for any candidate values of $\mathrm{T}$ and $\mathrm{K}$, and thus obtain the allowable values. The objective is to identify the optimum " $\mathrm{T}$ " and " $\mathrm{K}$ " that have the lowest possible CRF that satisfies maximum allowable MFDT. The whole problem complex is illustrated in Fig. 13, where both CRF and MFDT with their respective limits are shown for different values of $\mathrm{T}$, versus different values of $\mathrm{N}$.

As illustrated, in accordance with $\mathrm{MFDT}_{\text {max }}=0.15$, each inspection interval has a maximum utilization limit after which a restoration task should be performed to reduce the MFDT level. As the graph shows, taking $\mathrm{T}=950 \mathrm{FH}$ we are allowed to continue with the maximum $\mathrm{K}=12$, i.e. up to $\mathrm{T}_{\mathrm{K}}=11400 \mathrm{FH}$ with $\mathrm{CRF}=0.1940$ (shown by the brown rectangular legend). This means that, in order to satisfy $\mathrm{MFDT}_{\text {max }}=0.15$, we can conduct restoration after a maximum of 12 inspections. However, if we select $\mathrm{K}=10$, not only the unavailability is still below $\mathrm{MFDT}_{\text {max }}$, but also we can gain a lower CRF of 0.1893 . Hence, the decision would be $\mathrm{T}=950$ and $\mathrm{K}=10$. As the graph shows, all the optimum combinations of $\mathrm{T}$ and $\mathrm{K}$ shown in Fig. 10 are still valid for selection, and hence the decision will be the same and as follows:

1) To perform an inspection at every $B$ check, i.e. "T $=1000 \mathrm{FH}$ " and

2) To perform a restoration task at the $\mathrm{D}$ check, i.e. "T=10000FH".

In the case of an operational limit, when it is not possible to remove the component for restoration, we are allowed to postpone the restoration task until the next inspection, i.e. until $\mathrm{N}=11$, meaning that an extra $1000 \mathrm{FH}$ is allowable, to use the component, to satisfy $\mathrm{MFDT}_{\mathrm{Max}}=0.15$, and to meet the operational limit, but this results in a higher CRF.

If, in a specific case, the exact optimal values of $\mathrm{T}$ and $\mathrm{K}$ do not satisfy Eq. 15, then T, $\mathrm{K}$ or both parameters must be changed to reduce the $\mathrm{MFDT}_{(\mathrm{T}, \mathrm{K})}$ below $\mathrm{MFDT}_{\text {max }}$. This is shown in Fig. 14, where MFDT $_{\max }$ is set to 0.05 for the same condition as those illustrated in Fig. 13. As is evident, by reducing $\mathrm{MFDT}_{\max }$, the $\mathrm{K}_{\max }$ decreases and CRF increases. In comparison with the case where $\mathrm{MFDT}_{\max }=0.15$, none of the optimal points meet the $\mathrm{MFDT}_{\max }=0.05$ requirements.

In general, if the $(T, K)$ is the only minimum of CRF, it is obvious that $\mathrm{CRF}$ increases gradually when $\mathrm{T}$ or $\mathrm{K}$ move away from optimum combination of $(\mathrm{T} \text { and } \mathrm{K})_{\mathrm{op}}$. Hence, by reducing $\mathrm{K}$, we can reach an applicable combination of $\mathrm{T}$ and $K$ (e.g. $K=7$ for $T=950$ ), but this results in a higher CRF.

Comparing the applicable values of $\mathrm{K}$ and $\mathrm{T}$, the one which has the lowest CRF should be selected, and in this case $\mathrm{T}=850$ and $\mathrm{K}=8$ are selected. Any additional reduction of the unavailability below MFDT $_{\max }$ leads to an inessential increase in the total task cost. However, in order to take a decision for task packaging, some adjustment is necessary. Table II shows the applicable options for decisions. As is evident, option 1, 2 and 3 are not suitable for any of the check packages (i.e. $\mathrm{A}_{1}=250 \mathrm{FH}, \mathrm{A}_{2}=500 \mathrm{FH}, \mathrm{B}=1000 \mathrm{FH}$,
Table II: Options for task selection

\begin{tabular}{|l|l|l|l|l|l|}
\cline { 2 - 6 } \multicolumn{1}{c|}{} & \multicolumn{5}{c|}{ Options } \\
\cline { 2 - 6 } \multicolumn{1}{c|}{} & 1 & 2 & 3 & 4 & 5 \\
\hline Inspection Interval "T" & 750 & 850 & 950 & 1000 & 1050 \\
\hline Maximum K & 9 & 8 & 7 & 6 & 6 \\
\hline Restoration Time & 6750 & 6800 & 6650 & 6000 & 6300 \\
\hline CRF & 0.2111 & 0.2074 & 0.1893 & 0.2077 & 0.2117 \\
\hline
\end{tabular}

$\mathrm{C}=5000 \mathrm{FH}$, or $\mathrm{D}=10000 \mathrm{FH}$ ). Making an adjustment to the $\mathrm{T}$ and $\mathrm{N}$ may also lead to values exceeding the MFDT Max . However, option 4, i.e. $T=1000$ and $K=6$, is well suited to task packaging. Summing up, the following tasks will be selected:

1) Performing an inspection at every $\mathrm{B}$ check, i.e. "T $=1000 \mathrm{FH}$ " and

2) Performing a restoration task at " $\mathrm{T}=6000 \mathrm{FH}$ ".

In fact, it is not possible to include the restoration task permanently into a check package, but the planning engineers have the possibility of including the restoration task in the first B check after the $\mathrm{C}$ inspection, or even in the $\mathrm{C}$ check, depending on the situation and planning criteria.

In the case of an operational limit, when it is not possible to remove the component for restoration, we can still postpone the restoration task, by reducing the inspection interval to a value that reduces the MFDT below MFDT $_{\text {Max }}$. Fig. 15 shows a situation where, with inspection at every $\mathrm{T}=1000 \mathrm{FH}$, we have to perform a restoration task at $\mathrm{T}_{\mathrm{K}}=6000 \mathrm{FH}$. As the figure shows, reducing the inspection interval to $\mathrm{T}=500 \mathrm{FH}$ reduces the MFDT level, and we will have the possibility of postponing the task for an additional 2250FH. However, such a postponement would affect the $\mathrm{CRF}$, and another trade-off analysis is needed to evaluate

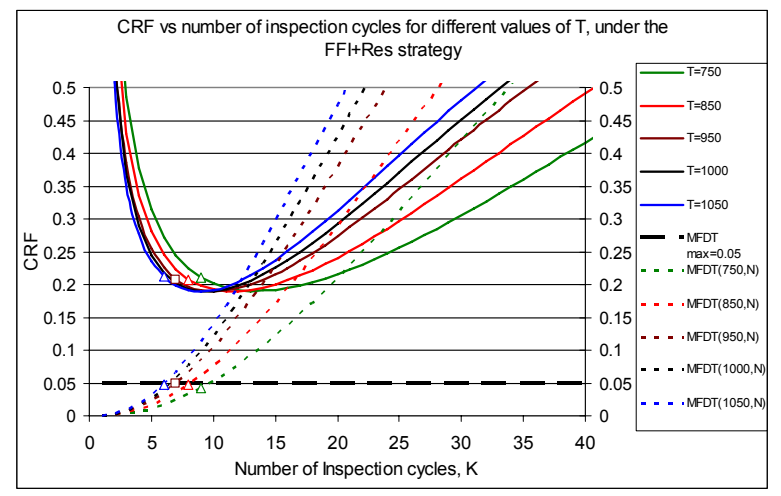

Figure 14: Comparison of cost rate function versus MFDT for different $\mathrm{T}$ values, under the FFI+Res strategy.

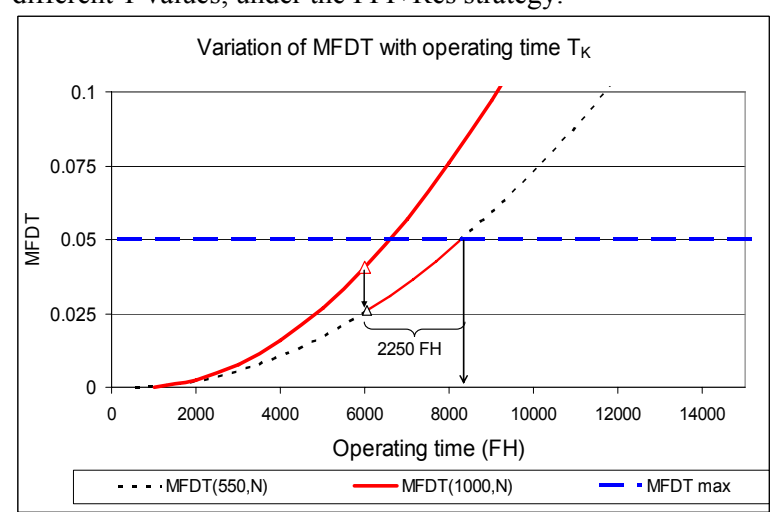

Figure 15: Possibility of inspection postponement in accordance with MFDT max. 
whether this is acceptable or not.

\section{DISCUSSION AND CONCLUSION}

A cost model has been developed to identify the optimum interval and frequency of inspection in the Failure Finding Inspection (FFI) strategy and the optimum interval and frequency of inspection and restoration in the strategy combining inspection with restoration after a specific number of inspections. In the model the opportunity cost of the aircraft's lost production due to maintenance downtime is considered. Limiting values have been determined for the cases where inspection interval $\mathrm{T}$, and number of inspection cycles $\mathrm{N}$, tends to infinity and also when there are no undesired consequences of failure i.e. when the cost of accident is equal to zero $\left(\mathrm{C}_{\mathrm{A}} \cdot \varphi=0\right)$. These values give an idea to the analysts about the cost per unit of time, in a long run, i.e. a life cycle view.

The interval unavailability behaviour has been discussed and, using an example, maintenance task selection for the "non-safety effect" and the "safety effect" categories of hidden failure has been discussed, and the optimum inspection and restoration interval for both categories has been defined. Vaurio's approach has been verified in the application of aircraft operation, and the accuracy of approximation of that approach has also been checked in that context.

The study shows that, depending on the failure data and cost parameters, a mixture of failure finding and restoration actions can not only increase the cost-effectiveness of maintenance, but also may improve the availability performance of the unit. Hence, a mixed strategy, i.e. a combination of maintenance tasks, should be considered in formal maintenance task development even for the "nonsafety effect" category of failure.

In the case of an operational limitation, when it is not possible to remove the unit for restoration, it has been shown that even when the component undergoes aging, by reducing the inspection interval, it is possible to postpone the inspection for a limited time, of course with a higher cost.

As simulation is used with hypothetical data, further analysis needs to be performed with field data from real situations. The method can also be used for non-aged units. If data is available, the effectiveness of restoration action can also be considered in the model, by some adjustments.

Summing up, by the incorporation of adequate modelling support, the current methods of developing a maintenance task can be considerably enhanced and based on a surer scientific foundation. Thereby, not only are the safety requirements fulfilled, but a lower maintenance cost per flight hour is also obtained simultaneously. This becomes more interesting when we consider a fleet of aircraft, and the opportunity that is lost due to a non-optimized maintenance programme. By this approach, it is possible to recognize the real contribution of maintenance in the total operating cost and to evaluate whether performing redesign and including a monitoring system such as BIT, increasing the redundancy, or improving the system maintainability performance reasonably decrease the cost per flying hour and provide more available flight hours for the business. This approach makes the aircraft maintenance programme properly optimized, which makes the aircraft type attractive to the operators and contributes to the airline's financial success.

\section{REFERENCES}

[1] F.S. Nowlan and H.F. Heap, Reliability Centered Maintenance. San Francisco: United airlines, 1978.

[2] U. Kumar and P.A. Akersten, "Availability and Maintainability," in Encyclopedia of Quantitative Risk Analysis and Assessment, E. L. Melnik and B. S. Everitt, Eds. Chichester, UK: John Wiley \&Sons, 2008, pp.77-84.

[3] J. D. Andrews and T. R. Moss, Reliability and risk assessment. $2^{\text {nd }}$ ed. London, UK: Professional Engineering Publisher Limited, 2006.

[4] C.E. Ebeling, An introduction to reliability and maintainability engineering. New York: McGraw Hill, 1997.

[5] ATA MSG-3: Operator/Manufacturer Scheduled Maintenance Development, Air Transport Association of America, Pennsylvania, 2007.

[6] A.K.S. Jardine and A.H.C. Tsang, Maintenance, replacement and reliability: theory and application. USA: Taylor \& Francis, 2006.

[7] B. Klefsjö and U. Kumar, "Goodness-of-fit tests for the power-law process based on the TTT-plot," IEEE Trans. Reliab., vol. 41, pp. 593-598, Dec. 1992.

[8] E. S. Rigdon and PA. Basu, Statistical Methods for the Reliability of repairable systems. New York: John Wiley and Sons, 2000.

[9] J. K. Vaurio, "On time dependent availability and maintenance optimization of standby units under various maintenance policies," Reliability Engineering and System Safety, vol. 56, no.1, pp. 79-89, 1997

[10] J. K. Vaurio, "Optimization of test and maintenance intervals based on risk and cost," Reliability Engineering and System Safety, vol. 49, no. 1, pp. 23-36, 1995.

[11] J. K. Vaurio, "Availability and Cost Functions for Periodically Inspected Preventively Maintained Units," Reliability Engineering and System Safety, vol. 63, no. 2, pp. 133-140, 1999.

[12] M. Rausand and J. Vatn, "Reliability modelling of surface controlled subsurface safety valves," Reliability Engineering and System Safety, vol. 61, no.1-2, pp. 159-166, 1998.

[13] C. E. Barroeta and M. Modarres, "Risk and Economic Estimation of Inspection Interval for Periodically Tested Repairable Components," American Nuclear Society International Topical Meeting on Probabilistic Safety Analysis, PSA, San Francisco, 2005, pp. 952-960.

[14] B. Lienhardt, E. Hugues., C. Bes and D. Noll, "Failure-Finding Frequency for a Repairable System Subject to Hidden Failures." Journal of Aircraft, vol. 45, no.5, pp. 1804-1809, 2007.

[15] H. Ascher. and H. Feingold, Repairable Systems Reliability: Modeling, Inference, Misconceptions and their Causes. New York: Marcel Dekker, 1984

[16] M. Rausand and A. Høyland, System Reliability Theory: Models, Statistical Methods and Applications. Hoboken, New Jersey: John Wiley; 2004.

[17] M. Modarres, Risk Analysis in Engineering: Techniques, Tools, and Trend. NW: Taylor \& Francis, 2006.

[18] AC19-25: Certification Maintenance Requirements, Federal Aviation Administration, US Department of Transportation, 1994.

[19] T. Aven and E. Abrahamsen, "On the Use of Cost-Benefit Analysis in ALARP Processes," International Journal of Performability Engineering, vol. 3, no. 3, pp. 345-353, 2007.

Alireza Ahmadi is a Ph.D. candidate at the Division of Operation and Maintenance Engineering, Luleå University of Technology (LTU), Sweden. $\mathrm{He}$ has received his Licentiate degree in Operation and Maintenance Engineering in 2007. Alireza has more than 10 years of experience in civil aviation maintenance as licensed engineer, and production planning manager. His research topic is related to the application of RAMS to improve aircraft maintenance program development.

Dr. Uday Kumar is a Professor of Operation and Maintenance Engineering at Luleå University of Technology, Luleå, Sweden. His research and consulting efforts are mainly focused on enhancing the effectiveness and efficiency of maintenance process at both operational and strategic levels and visualizing the contribution of maintenance in an industrial organization. He has published more than 175 papers in peer reviewed international journals, proceedings of conferences, and chapters in books. He is reviewer and member of the Editorial Advisory Board of several international journals. His research interests are Maintenance Management and Engineering, Reliability and Maintainability Analysis, LCC, etc. 